\title{
Original \\ Article \\ Mammographic density as a risk factor for breast cancer in a low risk population
}

\author{
Attam A, Kaur N, Saha S, Bhargava SK ${ }^{1}$ \\ Departments of General Surgery and ${ }^{1}$ Radiology, University College of Medical Sciences and Guru Teg \\ Bahadur Hospital, Delhi, India.
}

Correspondence to: Prof. Navneet Kaur, E-mail: dr_navkaur@hotmail.com

\begin{abstract}
BACKGROUND: Mammographic density is a function of abundance of epithelial and connective tissue in breast. It has been identified as an independent risk factor for breast cancer in studies in western populations. We conducted a case control study to evaluate the role of mammographic density as risk factor for the development of breast cancer in Indian patients. METHODS: One hundred and one cases of breast cancer and 123 healthy controls were included in the study. Mammographic density of the breast tissue of all controls and the contralateral breast of breast cancer patients was measured using a six category scale by a qualified radiologist. RESULTS: A low prevalence of dense mammographic patterns (16.3\% in controls and $26.7 \%$ in cases) was seen in the study population. Premenopausal women with breast density of $50 \%$ or more had 3.8 times risk of developing breast cancer than women with breast density of $<10 \%$. $(\mathrm{OR}=$ $3.86 ; 95 \% \mathrm{Cl}=1.4-10.1)$ In postmenopausal women with mammographically dense breast, no such increase in risk was noted. CONCLUSION: High mammographic density patterns are associated with an increased risk for the development of breast cancer in younger women in a low risk population, whereas no such increase in risk is seen in postmenopausal women.
\end{abstract}

Key words: Breast cancer, mammographic density.

\section{Introduction}

Breast cancer is the most common malignancy among women globally. In India, breast cancer, though less common than in western populations, has become the leading cancer in females in metropolitan cities like D elhi, M umbai, Bangalore, Kolkata and Bhopal overtaking carcinoma cervix, which was the number one cancer in the past. ${ }^{[1]} \mathrm{U}$ ntil recently, the main thrust in breast cancer control has been on early detection and treatment. But now the risk assessment and prevention of breast cancer is gaining importance. The risk factors for breast cancer in western populations have been extensively investigated and it has been found that life style related and reproductive factors are strongly associated with increased risk for breast cancer. H owever in low risk populations, prevalence of these factors is low. ${ }^{[2,3]}$ There is a constant search for other factors which may have a stronger association with an increased risk for developing breast cancer. Mammographic density is one such factor, which needs more evaluation.
M ammographic density is an expression of epithelial and connective tissue component of the breast and a large number of studies in western population have observed that mammographic density is an independent risk factor for breast cancer. ${ }^{[4,5]} \mathrm{H}$ owever, no information is available about mammographic density patterns in Indian women. H ence we conducted a case-control study to evaluate the role of mammographic density as a risk factor for developing breast cancer in our population.

\section{Materials and Methods}

A H ospital based Case-Control study was conducted prospectively from A pril 2004 to M arch 2005 in the department of surgery at UCMS and GTB hospital, $D$ elhi. O ne hundred and one consecutive patients with Biopsy/FN AC proven breast cancer were taken as cases. One hundred and twenty three consecutive women more than 35 years of age, presenting to the hospital with no complaints related to the breast or gynecological 
system were included as controls. An informed consent was obtained from all the subjects. Each control was examined in detail to exclude the presence of any breast lump and subjected to screening film mammography to exclude any in situ lesion or nonpalpable breast lesion.

Mammographic density of the breast tissue of all the controls and the contralateral breast of breast cancer patients was measured by a qualified radiologist who was blinded to the identity of case subjects and control subjects [Figure 1]. Classification of densities using a six-category scale was done as described by Boyd et al. ${ }^{[6]}$

\section{Statistical methods}

Mean age of both the groups was compared with unpaired $t$ test. Categorical variables were compared with chi square test. Odds ratio for mammographic density was calculated using univariate logistic regression analysis. P value below five percent was taken as a significant result.

\section{Results}

A total of 101 histologically confirmed breast cancer patients were studied and compared with a group of 123 controls. The mean age of control group was $47.14 \pm 8.85$ years and the case group was $49.93 \pm$ 11.5 years and thus the two groups were comparable $(P=0.094)$. Forty three percent of controls and forty six percent of cases were premenopausal. The distribution of subjects according to menopausal status is shown in [Table 1]. Menopause was defined as the time when there has been no menstrual period for 12 consecutive months and no other biological or physiological cause can be identified.

The two groups were compared for distribution
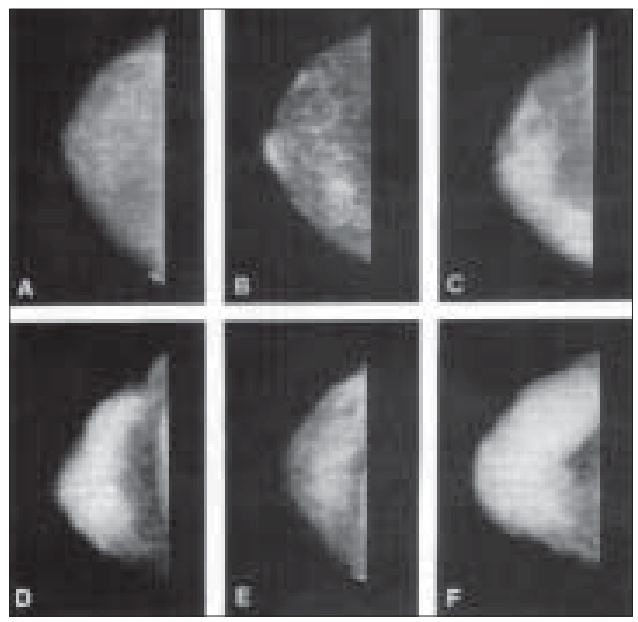

Figure 1: Mammographic densities
Table 1: Distribution according to Menopausal status

\begin{tabular}{lccccc}
$\begin{array}{l}\text { Menopausal } \\
\text { status }\end{array}$ & $\begin{array}{c}\text { Control } \\
\text { group } \\
\mathbf{N}\end{array}$ & $\begin{array}{c}\text { Case } \\
\text { group } \\
\%\end{array}$ & $\begin{array}{c}\text { Total } \\
\mathbf{N} \\
\mathbf{N}\end{array}$ & $\%$ & \\
\hline Premenopausal & 53 & 43.1 & 47 & 46.5 & 107 \\
\hline Post menopausal & 54 & 43.9 & 35 & 34.7 & 95 \\
\hline Hysterectomy & 6 & 4.9 & 8 & 7.9 & 14 \\
\hline Perimenopausal & 10 & 8.1 & 11 & 10.9 & 22 \\
\hline Total & 123 & 100 & 101 & 100 & 238 \\
\hline
\end{tabular}

$P$ value 0.455

according to mammographic density (\%) for all age groups combined. We found no significant difference in distribution of subjects in the two groups [Table 2]. D ense mammographic patterns $(>50 \%)$ were seen in $16.3 \%$ of control subjects and $26.7 \%$ of cases. Since menopause is an event which has major influence on the changes in breast tissue, both the groups were reanalyzed after dividing the study subjects into two age groups. This division was based on the mean age at menopause for both the groups combined ensuring minimal overlap of pre and postmenopausal patients in either group [Tables 3 and 4]. In premenopausal group (age $\leq 47$ years) $20.5 \%$ controls and $44.9 \%$ of cases had mammographic density $>50 \%$. The difference in mammographic density in the case and control group was found to be significant $(P=0.039)$. In postmenopausal group (age $=47$ years) dense patterns were seen in $10.9 \%$ of controls and $9.6 \%$ of cases. There was no significant difference between two groups.

\section{Univariate logistic regression analysis}

$\mathrm{M}$ ammographic density was reanalyzed using univariate logistic regression analysis [Table 5]. We found that for

Table 2: Distribution according to

Mammographic density (\%) for all age groups.

\begin{tabular}{lccccc}
$\begin{array}{l}\text { Mammographic } \\
\text { density (\%) }\end{array}$ & $\begin{array}{c}\text { Control } \\
\text { group } \\
\mathbf{N}\end{array}$ & $\begin{array}{c}\text { Case } \\
\text { group } \\
\%\end{array}$ & $\begin{array}{c}\text { Total } \\
\mathbf{N} \\
\mathbf{N}\end{array}$ & $\%$ & \\
\hline 0 & 27 & 21.9 & 10 & 9.9 & 37 \\
\hline $0-<10$ & 33 & 26.8 & 28 & 27.7 & 61 \\
\hline $10-<25$ & 21 & 17.1 & 20 & 19.8 & 41 \\
\hline $25-<50$ & 22 & 17.9 & 16 & 15.8 & 38 \\
\hline $50-<75$ & 15 & 12.2 & 16 & 15.8 & 31 \\
\hline$\geq 75$ & 5 & 4.1 & 11 & 10.9 & 16 \\
\hline Total & 123 & 100 & 101 & 100 & 238 \\
\hline
\end{tabular}

$P$ value 0.094 
Table 3: Distribution according to Mammographic density (\%) for age group $\leq \mathbf{4 7}$ years

\begin{tabular}{lccccc}
\hline $\begin{array}{l}\text { Mammographic } \\
\text { density(\%) }\end{array}$ & $\begin{array}{c}\text { Control } \\
\text { group } \\
\mathbf{N}\end{array}$ & $\begin{array}{c}\text { Case } \\
\text { group } \\
\%\end{array}$ & $\begin{array}{c}\text { Total } \\
\mathbf{N} \\
\mathbf{N}\end{array}$ & $\%$ & \\
\hline 0 & 10 & 14.7 & 1 & 2.0 & 11 \\
\hline $0-<10$ & 17 & 25.0 & 10 & 20.4 & 27 \\
\hline $10-<25$ & 10 & 14.7 & 8 & 16.3 & 18 \\
\hline $25-<50$ & 17 & 25.0 & 8 & 16.3 & 25 \\
\hline $50-<75$ & 9 & 13.2 & 13 & 26.5 & 22 \\
\hline$\geq 75$ & 5 & 7.3 & 9 & 18.4 & 14 \\
\hline Total & 68 & 100 & 49 & 100 & 117 \\
\hline$P$ value 0.039 (Significant) & & & & &
\end{tabular}

Table 4: Distribution according to Mammographic density (\%) for age group $>47$ years

\begin{tabular}{lccccc}
\hline $\begin{array}{l}\text { Mammographic } \\
\text { density (\%) }\end{array}$ & $\begin{array}{c}\text { Control } \\
\text { group } \\
\mathbf{N}\end{array}$ & $\begin{array}{c}\text { Case } \\
\text { group } \\
\%\end{array}$ & $\begin{array}{c}\text { Total } \\
\mathbf{N} \\
\mathbf{N}\end{array}$ & $\%$ & \\
\hline 0 & 17 & 30.9 & 9 & 17.3 & 26 \\
\hline $0-<10$ & 16 & 29.1 & 18 & 34.6 & 34 \\
\hline $10-<25$ & 11 & 20.0 & 12 & 23.0 & 23 \\
\hline $25-<50$ & 5 & 9.1 & 8 & 15.4 & 13 \\
\hline $50-<75$ & 6 & 10.9 & 3 & 5.8 & 9 \\
\hline$\geq 75$ & 0 & 0 & 2 & 3.8 & 2 \\
\hline Total & 55 & 100 & 52 & 100 & 107 \\
\hline$P$ value 0.284 & & & & &
\end{tabular}

women with breast density of $50 \%$ or more, the breast cancer risk rose by two-fold as compared to women with breast density of $<10 \%$. $(\mathrm{OR}=2 ; 95 \% \mathrm{Cl}=$ 1- 4.3) We further divided the study population in two groups ( $\leq 47$ years and $>47$ years; based on the mean age at menopause for the study population). For premenopausal women, breast density of $50 \%$ or more raised risk by 3.86 times compared to women with mammographic density of $<10 \%$ (OR $=3.86$ : $95 \%$ $\mathrm{Cl}=1.4-10.1) \mathrm{H}$ owever for women $>47$ years the association was not as consistent $(\mathrm{OR}=1.01 ; 95 \%$ $\mathrm{Cl}=0.2-3.7)$

\section{Discussion}

\section{Mammographic density and parenchymal patterns}

The breast is made up of fat, stroma, and epithelial tissue. On a mammogram, fat tissue appears translucent, whereas stromal and epithelial tissues are radiographically dense. Mammographic parenchymal patterns were first described by Wolfe as consisting of predominantly fat ( 1 pattern), having gradually increasing ductal prominence (P1 and P2 patterns), or having diffuse or nodular density (DY pattern). ${ }^{.7]}$ Several additional classification schemes have been used subsequently, including a description of the overall percentage of dense tissue seen on the mammogram (i.e. mammographic density). ${ }^{[6]}$

A large number of case-control and cohort studies have observed a significant positive relationship between dense mammographic pattern and subsequent risk of breast cancer. ${ }^{[4,5,8-10]} \mathrm{R}$ isk conferred by mammographic density has been found to be independent of other well established risk factors. M ore importantly, these effects

\section{Table 5: Univariate logistic regression analysis}

\begin{tabular}{|c|c|c|c|c|}
\hline Risk factors & Beta & Odds ratio & $\mathrm{Cl}$ of odds ratio & $P$ value \\
\hline \multicolumn{5}{|c|}{ Mammographic density (\%) } \\
\hline $0-<10$ & 1.000 & & & \\
\hline $10-<50$ & 0.279 & 1.322 & $0.725-2.411$ & 0.363 \\
\hline $50-\geq 75$ & 0.757 & 2.132 & $1.051-4.321$ & 0.036 \\
\hline \multicolumn{5}{|c|}{ Mammographic density (\%) in $<=47$ years age group } \\
\hline $0-<10$ & & 1.000 & & \\
\hline $10-<50$ & 0.375 & 1.455 & $0.571-3.704$ & 0.432 \\
\hline $50-\geq 75$ & 1.350 & 3.857 & $1.462-10.173$ & 0.006 \\
\hline \multicolumn{5}{|c|}{ Mammographic density (\%) in $>47$ years age group } \\
\hline $0-<10$ & & 1.000 & & \\
\hline $10-<50$ & 0.424 & 1.528 & $0.665-3.508$ & 0.318 \\
\hline $50-\geq 75$ & 0.018 & 1.019 & $0.280-3.705$ & 0.978 \\
\hline
\end{tabular}


persist for 10 or more years and have been noted for both premenopausal and postmenopausal women of all ages. ${ }^{[5]}$ Association of mammographic density with known reproductive factors for breast cancer has also been reported in the literature. ${ }^{[5,11]}$

In a study by Byrne et al, consisting of almost 2000 case subjects and more than 2000 control subjects, breast cancer risk rose more than four-fold for women with mammographic density of $75 \%$ or more compared to women with mammographic density of $0 \%{ }^{[5]}$ Muskarinec et al, conducted a multiethnic case control study and found that women with breast density of more than $50 \%$ had 3.6 times higher risk of breast cancer than women with less than $10 \%$ density, but the risk varied with ethnicity. Whereas the odds ratio was 5.3 for Caucasians and 4.2 for $\mathrm{N}$ ative $\mathrm{H}$ awaiians, it was only 3.2 for women of Japanese ancestry. ${ }^{[9]}$

A recent study by Boyd et al, with 1112 matched case control pairs, showed that women with density of $75 \%$ or more had increased risk of breast cancer compared to women with $<10 \%$ density (odds ratio -4.7 ). This risk persisted for eight years and was greater in younger women than in older women. ${ }^{[10]}$

Mammographic density is a function of the abundance of epithelial and connective tissue in the breast, but a cancer and normal tissue can have similar radiographic attenuation, which can make both appear radiodense or white on a mammogram. Therefore, it is possible that the risk associated with mammographic density is due to the masking effect i.e. extensive breast density can hide a cancer. H owever, Boyd et al, reported an association between breast cancer and extensive mammographic density even when the density was observed as long as eight years before a diagnosis of breast cancer, indicating the association between extensive mammographic density and increased risk of breast cancer is not entirely due to the masking effect. ${ }^{[10]}$

In our study, dense mammographic patterns (>50\% breast density) were seen in 16.3 percent of controls and 26.7 percent of cases. This prevalence was similar to the study by Boyd et al. ${ }^{[10]}$ On univariate analysis, we found that premenopausal women with dense mammographic patterns had a high risk of developing breast cancer whereas in post menopausal women no such association was seen. This can be probably be explained by fall in estrogen and progesterone levels in postmenopausal women and hence cessation of stimulation for breast epithelial cell proliferation by these hormones.

Thus, we found that the highest category of percent breast density may be helpful in identifying women for screening purposes, who are at an increased risk for developing breast cancer. H owever, breast density does not identify all women who will develop breast cancer because many cancers were found in women with low density on mammography. Thus instead of influencing whether a women receives screening, knowledge of a woman's breast density might be useful in determining the frequency of screening. Digital mammography, $\mathrm{U}$ Itrasonography and magnetic resonance imaging may increase the detection of cancer in women who have extensive mammographic density. ${ }^{[11]}$

Likely limitations of our study are small sample size and the lack of follow-up. Some of the women from control group may develop breast cancer in future and this information will alter our results. Classification of breast densities using computer assisted methods may have further enhanced accuracy of our findings. $O$ ther limitations are non evaluation of BMI, parity and weight, which are both related to mammographic density and breast cancer, however, mammographic density has been shown to be an independent risk factor for breast cancer in previous studies. ${ }^{[5,10]} \mathrm{A}$ larger multicenter study with follow-up, as well as a more precise method for assessment of breast density is recommended to evaluate further the role of mammographic density as a risk factor for breast cancer in low risk populations.

\section{References}

1. Two-year report of the population based cancer registries 19971998: National Cancer Registry Programme. New Delhi: Indian Council of Medical Research; 2002.

2. Rao DN, Ganesh B, Desai PB. Role of reproductive factors in breast cancer in a low risk area: A case control study. $\mathrm{Br} J$ Cancer 1994;70:129-32.

3. Gajalakshmi CK, Shanta V, Swaminathan R, Sankaranarayanan R, Black RJ. A population based survival study on female breast cancer in Madras, India. Br J cancer 1997;75:771-5.

4. Oza AM, Boyd NF. Mammographic parenchymal patterns: A marker of breast cancer risk. Epidemiol Rev 1993;15: 196-208.

5. Byrne C, Schairer C, Wolfe J, Parekh N, Salane M, Brinton LA, et al. Mammographic features and breast cancer risk: Effects with time, age, and menopause status. J Natl Cancer Inst 1995;87:1622-9.

6. Boyd NF, Jensen HM, Cooke G, Lee Han H. Relationship between mammographic and histologic risk factors for breast cancer. J Natl Cancer Inst 1992;84:1170-9.

7. Wolfe JN. Risk for breast cancer development determined by mammographic parenchymal pattern. Cancer 1976;37:2486-92.

8. Adami HO, Signorello LB, Trichopoulos D. Towards an understanding of breast cancer etiology. Semin Cancer Biol 1998;8:255-62.

9. Maskarinec G, Pagano I, Lurie G, Wilkens LR, Kolonel LN. Mammoraphic density and breast cancer risk. Am J Epidemol 2005; 162:743-52.

10. Boyd NF, Go H, Martin LJ, Sun L, Stone J, Fishell E, et al. Mammographic density and the risk and detection of breast cancer. N Engl J Med 2007;356:227-36.

11. Pisano ED, Gatsonis C, Hendrick E, Yaffe M, Baum JK, Acharyya S. Diagnostic performance of digital versus film mammography for breast cancer screening. N Engl J Med 2005;353:1773-83.

Source of Support: Nil, Conflict of Interest: None declared. 